${ }^{1}$ Municipal Government of São Miguel do Oeste, SC, Brazil

${ }^{2}$ Dentistry Postgraduate Program, Federal University of Pelotas UFPel, Pelotas, RS, Brazil

${ }^{3}$ Health Sciences Postgraduate Program, Community University of the Region of Chapecó Unochapecó, Chapecó, SC, Brazil

Corresponding author: Sinval Adalberto Rodrigues-Junior Universidade Comunitária da Região de Chapecó

Área de Ciências da Saúde - Caixa postal 1141

Servidão Anjo da Guarda, n. 295-D

- Bairro Efapi

CEP 89809-000 - Chapecó - SC

- Brasil

Phone number: (49) 3321-8069

E-mail: rodriguesjunior.sa@

unochapeco.edu.br

Received: April 27, 2018

Accepted: November 24, 2018

\section{Denture disinfection using Salvia officinalis L.: microbial load and selected properties of PMMA}

\author{
Débora Oro Ferrari', Rafael Guerra Lund², Luana Zanella ${ }^{3}$, \\ Walter Antônio Roman Júnior ${ }^{3}$, Sinval Adalberto \\ Rodrigues-Junior ${ }^{3}$
}

Denture use may aggravate the occurrence of oral infections, considering it enhances microbial adherence. Aim: This study assessed the reduction of microbial loads of Candida albicans, Staphylococcus aureus, and Klebsiella oxytoca by disinfecting the polymethylmethacrylate (PMMA) of complete dentures with hydroalcoholic extract of Salvia officinalis. Additionally, the effect of such extract on the properties of PMMA was examined. Methods: Microorganisms were isolated from saliva samples collected from complete denture wearers. The hydroalcoholic extract of $S$. officinalis was produced according to the Brazilian Pharmacopoeia 5. The PMMA specimens $(n=188)$ were immersed in microbial inoculum and incubated at $37^{\circ} \mathrm{C}$ for 16 hours per day. Then, they were subjected to a disinfection protocol for 30 days. The specimens were divided into five treatment groups: sterile saline solution $(0.85 \%$; control), $0.2 \%$ chlorhexidine digluconate, and hydroalcoholic extract of S. officinalis $(0.2 \%, 0.8 \%$, and $1.16 \%$ ). Microorganism adherence to the PMMA surface was also assessed, as well as surface roughness ( $R a$ in $\mu \mathrm{m}$ ) and color stability of the PMMA (mean $\triangle E$ ). Changes in microbial load and surface roughness after the disinfection protocol were verified with paired t-test. Substances at day 10, adherence, and color stability were compared by the Kruskall-Wallis and Mann-Whitney tests, and one-way ANOVA was used to compare substances at the beginning and end of the experiment $(\alpha=0.05)$. Results: The $1.16 \%$ $S$. officinalis extract significantly reduced the microbial load of all the microorganisms after 30 days of disinfection $(p<0.05$ ). The microbial load of $K$. oxytoca was also reduced at lower concentrations of the S. officinalis extract $(0.2 \%$ and $0.8 \%)(p<0.02)$. Antimicrobial and anti-adherent effects against microorganisms isolated from the oral cavity were observed. There was no significant change in surface roughness ( $p>0.05$ ) and color stability was significantly higher in the control group ( $p<0.0001)$. Conclusions: The hydroalcoholic extract of $S$. officinalis may be used as a disinfectant solution for dentures.

Keywords: Colony count, microbial. Denture cleansers. Plant extracts. Polymethyl Methacrylate. 


\section{Introduction}

Denture use may aggravate the occurrence of oral infections, considering it enhances microbial adherence, particularly in poorly sanitized conditions ${ }^{1}$. Among the pathogens particularly implicated in the etiology of oral infections, gram-positive cocci, enterobacteria, and Candida albicans have been frequently associated with several types of infections in denture wearers ${ }^{2-4}$. Disinfecting dentures is essential to reduce the number of microorganisms present on their surface and consequently to reduce the incidence of oral infections ${ }^{5}$.

Microorganism adherence occurs through biofilm formation, especially on surfaces kept in direct contact with the oral mucosa ${ }^{6}$. Different methods have been proposed to disinfect the polymethylmethacrylate (PMMA) of dentures. Professional cleaning alternatives involve ultrasonic bath, immersion in glutaraldehyde, sodium hypochlorite, or alcohol-based solutions, and microwaving ${ }^{7,8}$. Some of these disinfection methods, although effective, may have a negative effect on the properties of $\mathrm{PMMA}^{8}$.

Overnight denture immersion in cleaning solutions has also been indicated for disinfecting purposes. Immersion in chlorhexidine digluconate, alkaline peroxide, and sodium hypochlorite has been shown to produce a significant disinfecting effect ${ }^{9,10}$. However, the long-term contact of PMMA with these solutions has shown significant denture discoloration ${ }^{10,11}$.

Therefore, it may be important to acknowledge natural substances with antimicrobial potential to work as denture disinfectants. These substances should be easily obtained and widely used by the population. ${ }^{12}$ Plant extracts have shown significant results regarding antimicrobial potential in different conditions $3,12,13$.

In Brazil, the use of medicinal plants is common. Among the various species within the rich Brazilian biodiversity, Salvia officinalis L. (Lamiaceae) - popularly known as 'sage' - is native of the Mediterranean region ${ }^{14}$ and it has been widely used in dentistry. Sage oil presents antibacterial, antifungal, and antiviral activities ${ }^{15}$. Its leaves contain an essential oil (0.5-2.5\%) composed of cineol (up to 15\%), pinene, thujone, salvia, borneol, camphor, and other terpenoids, as well as flavonoids, tannins, acid triterpenes (ursolic and oleanolic acids), diterpenes, phenolic acids, amines, and vegetable acids $^{16}$. In the modern European herbal medicine, a gargle of sage tea is commonly recommended to treat sore throat, oral inflammations, and gingivitis ${ }^{15}$. It presents wound-healing, antimicrobial, regenerative, protective, anti-inflammatory, and deodorant effects. Essential oils, decoctions, and infusions with sage heal the oral cavity and accelerate recovery.

The antimicrobial effects of several plant species have been tested against a wide variety of oral cavity microorganisms ${ }^{13}$, but evaluating the amplitude of microbial reduction, especially on the denture surface, is still required ${ }^{12}$. Furthermore, it is worth noting the physical changes in dentures caused by the use of such extracts ${ }^{17}$.

Therefore, this study aimed to assess the antimicrobial effect of the hydroalcoholic extract of Salvia officinalis and to analyze its influence on surface roughness and color stability of the PMMA. The hypothesis to be tested was that sage extracts would sig- 
nificantly reduce the microbial load without significantly affecting the physical properties of the PMMA of dentures.

\section{Materials and methods}

This in vitro study was approved by the Institutional Research Ethics Committee, under protocol n. 1.752.675. Microbial samples were collected from 31 denture wearers selected by convenience at a private dental office located in the west region of the state of Santa Catarina, Brazil, in November/December 2016. Patients who wore complete dentures for at least one year, of any age and sex, and without oral lesion at the time of collection were included in the study. Those who underwent antimicrobial treatment were excluded.

Samples of saliva were seeded on plates of Sabouraud dextrose agar with chloramphenicol (Oxoid, Basingstoke, Hampshire, England), blood agar (Merck, Darmastadt, Germany), and MacConkey agar (Merck, Darmastadt, Germany), by the depletion technique. The plates were incubated in a bacteriological oven at temperature of $37^{\circ} \mathrm{C}$ for 24 hours. After this period, the plates were read. The identification of species considered the color aspects, morphology, and texture of the crop in the medium.

Microbial inoculums of $C$. albicans, S. aureus, and $K$. oxytoca were prepared from the cultures on the specific medium. Cell density was adjusted to a turbidity value equivalent to that of the McFarland standard solution (scale 1; approximately $3 \times$ $\left.10^{8} \mathrm{cells} / \mathrm{ml}\right)$.

The plant materials of S. officinalis L. were collected in the city of Pinhalzinho, Santa Catarina, Brazil $\left(26^{\circ} 49^{\prime} 19,16^{\prime \prime} \mathrm{S}\right.$ and $\left.53^{\circ} 00^{\prime} 59,52^{\prime \prime}\right)$. The exsiccate was identified by a curator at the Municipal Botanical Museum Herbarium of Curitiba, Paraná, Brazil and deposited under registration number MBM 388402.

The chemical characterization of $S$. officinalis was previously performed by Roman Junior et al. ${ }^{18}$ (2015) using high-performance liquid chromatography (HPLC). The tests were performed as described by Oliveira e Oliveira ${ }^{19}$ (2013) with modifications. The analysis and quantification of rosmarinic acid in the aqueous extract of S. officinalis by HPLC was possible by replacing the elution gradient, which was proposed by Oliveira e Oliveira ${ }^{19}$ (2013). Using the analytical curve $(y=0.462 x+1.623 ; r=0.999)$, a concentration of $3.53 \%$ was obtained for the plant material (Figure 1). The hydroalcoholic extract was produced according to the Brazilian Pharmacopoeia $5^{20}$. Briefly, the leaves were reduced to small fragments and subjected to drying $\left(25^{\circ} \mathrm{C}\right)$, protected from direct light and humidity. The dehydrated plant species was ground in a knife mill (Ciemlab $\circledast$, CE430) and sieved to select particles of $425 \mu \mathrm{m}$ (35 Tyler/Mesh). Aliquots of dry milled S. officinalis leaves ( $10 \mathrm{~g})$ were extracted successively with ethanol $(70 \%$, $200 \mathrm{ml}$ ) by maceration during 5 days. After filtration, the solvents were eliminated under reduced pressure using a rotary evaporator and the resulting hydroalcoholic extracts from S. officinalis were lyophilized, weighed, and stored in a freezer at $-20^{\circ} \mathrm{C}$.

A sample size of four test specimens per group was calculated for the color stability test using $G^{*}$ Power 3.1.9.2 (Universität Düsseldorf, Germany), considering a Type I error of $0.05,95 \%$ test power, one-tail, and effect size of 3.3 , based on a $\Delta E^{*}$ value that was considered clinically visible ${ }^{21}$. 
A

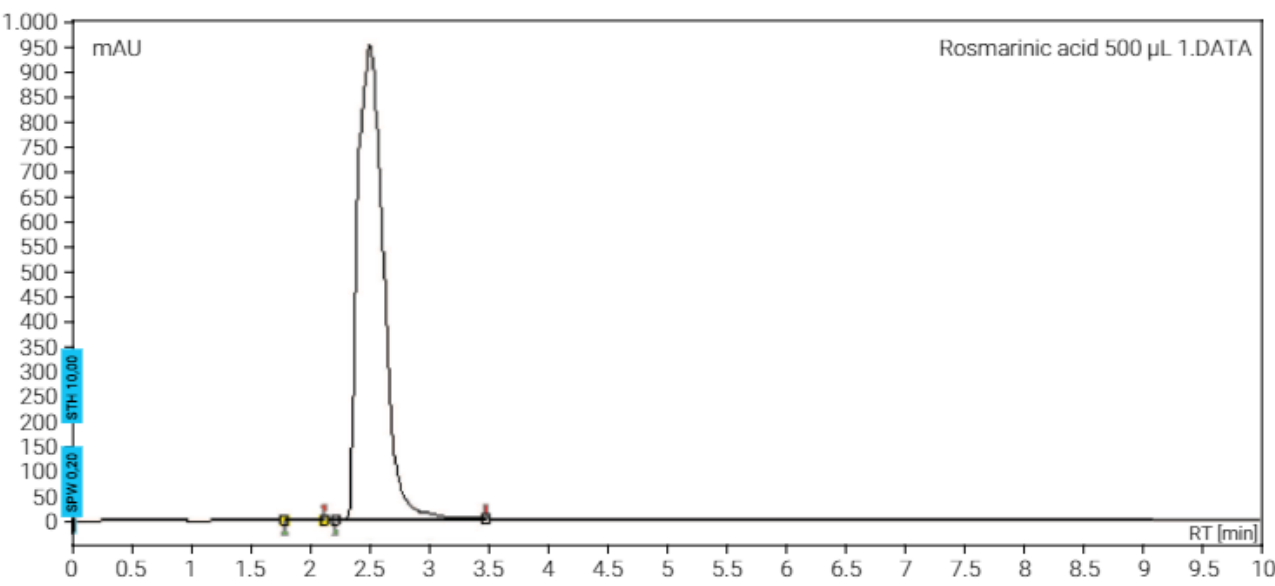

B

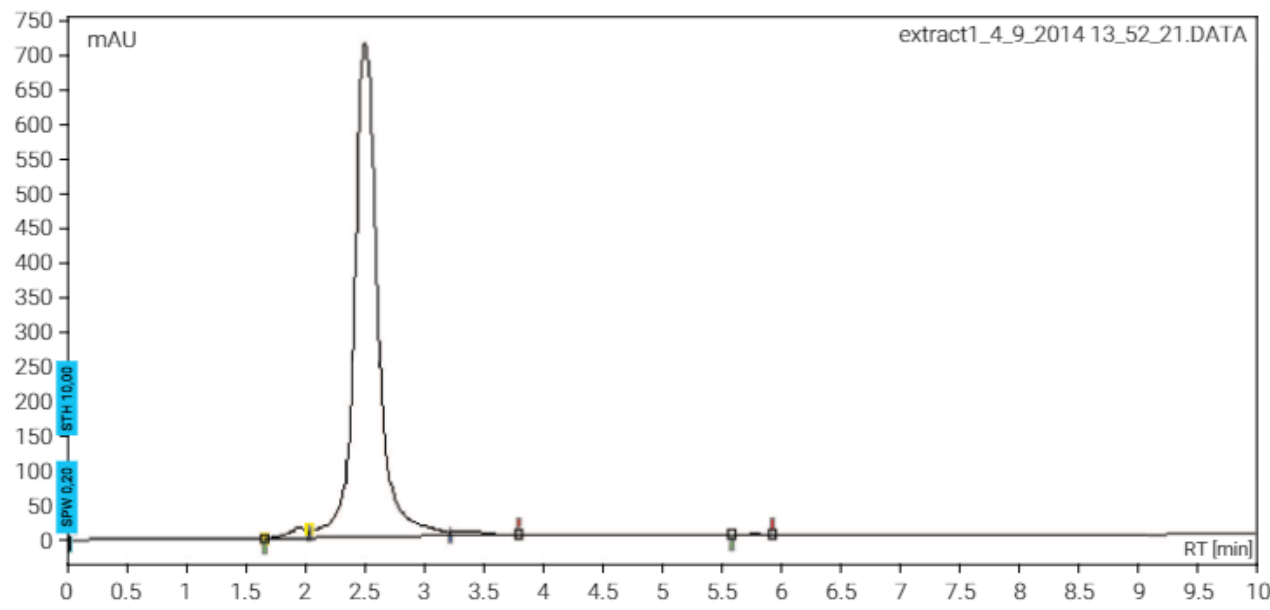

Figure 1. High-performance liquid chromatography of rosmarinic acid and aqueous extract of Salvia officinalis L. (Lamiaceae) leaves: A. rosmarinic acid $(500 \mu \mathrm{g} / \mathrm{mL}$ in $\mathrm{MeOH})$ (Rf: $2.5 \mathrm{~min})$; B. Aqueous extract of $S$. officinalis $(10 \mathrm{mg} / \mathrm{ml})$. Varian( ${ }^{\circledR}$ Chromatograph, Kromasil ${ }^{\circledR}$ ODS column $(5 \mu \mathrm{m}) \mathrm{C}-18$ reverse phase $(25 \times 4.5 \mathrm{~mm})$ at a temperature of $24^{\circ} \mathrm{C} \pm 2^{\circ} \mathrm{C}$. Solvents used: $\mathrm{MeOH}: \mathrm{H}_{3} \mathrm{PO}_{4}(0.1 \% \mathrm{v} / \mathrm{v})$ isocratic mode for $10 \mathrm{~min}$ with flow rate of $1 \mathrm{~mL} / \mathrm{min}$ and detection at $300 \mathrm{~nm}(\mathrm{n}=3)$. Source: Roman Júnior et al. ${ }^{18}$ (2015).

One hundred and eighty-eight disc-shaped specimens (10-mm diameter; 2-mm thick) were first prepared in wax and molded in gypsum plaster. Then, using the plaster molds, the discs were remade with thermopolymerizable polymethylmethacrylate (PMMA) resin (medium pink with veins; Clássico, Campo Limpo Paulista, São Paulo, Brazil). The discs were manually finished and consecutively followed by horsehair discs soaked in pumice stone (Asfer, São Caetano do Sul, São Paulo, Brazil). The specimens were polished with felt (Vipibril, Pirassununga, São Paulo, Brazil). Next, all specimens were exposed to ultraviolet light for 30 min on each side of the surface for disinfection.

The test specimens were immersed in liquid culture medium containing the microbial inoculum and incubated at $37^{\circ} \mathrm{C}$ for 16 hours/day ${ }^{12}$. Subsequently, they were sepa- 
rated into groups and disinfected in sterile saline solution ( $0.85 \%$; control), in a $0.2 \%$ chlorhexidine gluconate dental disinfectant (Riohex - Rioquímica, São José do Rio Preto, São Paulo, Brazil), or in hydroalcoholic extracts of S. officinalis at concentrations of $0.2 \%, 0.8 \%$, and $1.16 \%$. The specimens were immersed for 8 hours/day, simulating the nighttime, for a total of 30 days.

Surface roughness and color of the PMMA specimens were analyzed before and after the disinfection protocol (at 1 and 30 days). The color was analyzed with an Easyshade spectrophotometer (Vita Zahnfabrik, Bad Säckingen, Germany). Color change was calculated according to the CIE L*a*b* system ${ }^{22}$ and the resulting $\Delta \mathrm{E}^{*}$ was classified in three clinically significant intervals: $\Delta \mathrm{E}^{\star}<1$ (undetectable color change); $1<\Delta \mathrm{E}^{\star}<3.3$ (clinically acceptable color change); and $\Delta \mathrm{E}^{\star}>3.3$ (clinically unacceptable color change) ${ }^{17}$.

Surface roughness was analyzed with an RP-200 roughness meter (Instrutherm, São Paulo, SP, Brazil) with three parallel readings along the length of $4 \mathrm{~mm}$ and cut-off value of $0.8 \mathrm{~mm}$ to determine the mean surface roughness $(\mathrm{Ra}-\mu \mathrm{m})$.

To analyze the adhesion capacity of microorganisms to the PMMA surface, one test specimen from each sample was washed in sterile distilled water at day 10 to remove the poorly adhered cells. The specimen was sonicated in an ultrasonic cell disruptor (Unique USC 800A) at a frequency of $40 \mathrm{kHz}$, for $15 \mathrm{~min}$ at room temperature. Next, the samples were seeded in Plate Count Agar (PCA; Merck, Darmastadt, Germany) or Sabouraud dextrose agar plate with chloramphenicol (Oxoid, Basingstoke, Hampshire, England) and incubated for $24 \mathrm{~h}$ at $37^{\circ} \mathrm{C}$ to count the colony forming units (CFU) ${ }^{23}$.

The reduction of microbial load was evaluated by seeding and counting the CFUs on Sabouraud dextrose agar plate and PCA at 1 and 30 days of the protocol with the substances tested, so to observe whether there was a reduction in the number of CFUs over time. The culture medium was renewed during the experiment to prevent microbial reduction because of the lack of nutrients.

Normal data distribution was verified with the Anderson-Darling test. The before-after changes in microbial loads and surface roughness were compared by the paired t-test and Wilcoxon test. Substances at day 10 and color stability $(\Delta \mathrm{E})$ were compared by the Kruskal-Wallis and Mann-Whitney tests. The substances were compared at the beginning and end of the experiment using one-way ANOVA. The tests were performed with the Minitab 17.0 statistical package at $5 \%$ significance level.

\section{Results}

The microbial load of all microorganisms decreased at day 30. S. aureus significantly reduced in contact with both $1.16 \% \mathrm{~S}$. officinalis solution and $0.2 \%$ chlorhexidine solution. Similar results were found for $C$. albicans. $K$. oxytoca was more sensitive to the disinfectant solutions, significantly decreasing CFU counts when in contact with all the concentrations of $S$. officinalis extract and $0.2 \%$ chlorhexidine solution (Table 1 ). The ANOVA revealed no statistically significant difference between concentrations of S. officinalis extract for the three microorganisms. 
Table 1. Reduction in the microbial load of Staphylococcus aureus, Candida albicans and Klebsiella oxytoca $\left(\times 10^{7} \mathrm{CFU} / \mathrm{mL}\right)$ in the experimental groups at the end of the disinfection protocol $(\mathrm{N}=9)$

\begin{tabular}{lccccc}
\hline \multirow{2}{*}{ Microorganism } & Disinfectant & $\begin{array}{c}\text { Day 1 } \\
\text { Mean } \pm \text { SD }\end{array}$ & $\begin{array}{c}\text { Day } 30 \\
\text { Mean } \pm \text { SD }\end{array}$ & $\Delta$ & p \\
\hline S. aureus & Control & $37.00 \pm 2.65$ & $36.33 \pm 4.16$ & $0.67 \pm 1.53$ & 0.529 \\
\hline & S. officinalis 0.2\% & $37.00 \pm 2.00$ & $30.67 \pm 4.73$ & $6.33 \pm 3.51$ & 0.089 \\
\cline { 2 - 6 } & S. officinalis 0.8\% & $35.33 \pm 2.08$ & $31.00 \pm 3.61$ & $4.33 \pm 3.06$ & 0.133 \\
\cline { 2 - 6 } & S. officinalis 1.16\% & $34.33 \pm 4.51$ & $28.00 \pm 4.36$ & $6.33 \pm 1.53$ & $0.019^{*}$ \\
\cline { 2 - 6 } & Chlorexidine 0.2\% & $36.33 \pm 1.53$ & $6.63 \pm 0.42$ & $29.70 \pm 1.11$ & $0.0001^{*}$ \\
\hline C. albicans & Control & $38.67 \pm 4.04$ & $39.00 \pm 3.00$ & $-0.33 \pm 1.16$ & 0.667 \\
\hline & S. officinalis 0.2\% & $38.67 \pm 1.53$ & $37.00 \pm 2.65$ & $1.67 \pm 1.53$ & 0.199 \\
\hline S. officinalis 0.8\% & $40.00 \pm 2.00$ & $35.00 \pm 4.36$ & $5.00 \pm 2.65$ & 0.082 \\
\hline S. officinalis 1.16\% & $38.33 \pm 2.52$ & $33.33 \pm 3.21$ & $5.00 \pm 1.73$ & $0.038^{*}$ \\
\hline K. oxytoca & Chlorexidine 0.2\% & $40.67 \pm 2.08$ & $7.90 \pm 0.30$ & $32.77 \pm 2.31$ & $0.002^{*}$ \\
\hline C. Control & $34.33 \pm 3.06$ & $34.33 \pm 4.04$ & $0.00 \pm 1.00$ & 1.000 \\
\hline S. officinalis 0.2\% & $35.00 \pm 3.00$ & $29.33 \pm 2.08$ & $5.67 \pm 1.15$ & $0.014^{*}$ \\
\hline S. officinalis 0.8\% & $36.00 \pm 3.00$ & $28.00 \pm 4.36$ & $8.00 \pm 2.00$ & $0.020^{*}$ \\
\hline S. officinalis 1.16\% & $33.00 \pm 2.00$ & $26.33 \pm 2.08$ & $6.67 \pm 1.53$ & $0.017^{*}$ \\
\hline Chlorexidine 0.2\% & $36.00 \pm 3.61$ & $7.43 \pm 0.40$ & $28.57 \pm 3.30$ & $0.004^{*}$ \\
\hline
\end{tabular}

$\mathrm{MO}=$ microorganism. $\mathrm{SD}=$ Standard Deviation. $\Delta$ = Difference between means. * Statistically significant difference. Paired t-test $(p<0.05)$.

Table 2. Adherence of microorganisms $\left(x 10^{6} \mathrm{CFU} / \mathrm{mL}\right)$ on the PMMA surface among the experimental groups $(\mathrm{N}=9)$

\begin{tabular}{lccc}
\hline Disinfectant & S. aureus & C. albicans & K. oxytoca \\
\hline Control & $47.330^{\circ}$ & $36.667^{\mathrm{b}}$ & $43.000^{\mathrm{b}}$ \\
\hline S. officinalis $0.2 \%$ & $3.800^{\mathrm{b}}$ & $3.167^{\mathrm{a}}$ & $2.933^{\mathrm{a}}$ \\
\hline S. officinalis $0.8 \%$ & $3.767^{\mathrm{b}}$ & $2.967^{\mathrm{a}}$ & $3.900^{\mathrm{a}}$ \\
\hline S. officinalis $1.16 \%$ & $4.133^{\mathrm{b}}$ & $2.800^{\mathrm{a}}$ & $3.800^{\mathrm{a}}$ \\
\hline Chlorexidine $0.2 \%$ & $1.767^{\mathrm{a}}$ & $4.267^{\mathrm{a}}$ & $3.067^{\mathrm{a}}$ \\
\hline
\end{tabular}

Statistically significant differences among groups are indicated by different overlapping letters (within columns), Kruskal Wallis and Mann Whitney tests $(p<0.05)$.

In addition, significant reductions in microbial adherence to the PMMA surface were noted with all the disinfectant solutions when compared to the control group $(p<0.02)$. S. aureus showed a considerably lower adherence under the action of $0.2 \%$ chlorhexidine. A greater reduction in C. albicans and K. oxytoca adherence was observed in all groups (Table 2).

Color stability by means of $\Delta \mathrm{E}$ was significantly higher in the control group than in the other groups $(p<0.0001)$, with no significant differences among the experimental groups. The $\Delta \mathrm{E}$ values obtained for all experimental groups indicate a clinically unacceptable color change (Table 3).

A significant increase in PMMA roughness over 30 days was observed for $0.2 \%$ S. officinalis and no other group produced significant roughness changes at the end 
Table 3. Mean color change $(\Delta \mathrm{E})$ in dentures caused by the disinfectant substances at the end of the disinfection protocol.

\begin{tabular}{lcccc}
\hline Disinfectant & Mean \pm SD & Median & Minimum & Maximum \\
\hline Control & $2.78 \pm 2.29^{\mathrm{a}}$ & 1.74 & 0.29 & 9.03 \\
\hline S. officinalis 0.2\% & $6.94 \pm 3.40^{\mathrm{b}}$ & 6.29 & 1.32 & 15.01 \\
\hline S. officinalis 0.8\% & $7.54 \pm 6.09^{\mathrm{b}}$ & 6.15 & 0.01 & 22.98 \\
\hline S. officinalis 1.16\% & $7.26 \pm 4.55^{\mathrm{b}}$ & 6.19 & 1.02 & 17.35 \\
\hline Chlorexidine 0.2\% & $7.92 \pm 5.48^{\mathrm{b}}$ & 7.35 & 0.69 & 19.84 \\
\hline
\end{tabular}

Different letters indicate statistically significant differences between groups (Kruskal Wallis and Mann Whitney, $p<0.05)$

Table 4. Mean roughness ( $\mathrm{Ra}-\mu \mathrm{m})$ before and after the disinfection protocol.

\begin{tabular}{lcccc}
\hline Disinfectant & $\begin{array}{c}\text { Day 1 } \\
\text { Mean } \pm \text { SD }\end{array}$ & $\begin{array}{c}\text { Day 30 } \\
\text { Mean } \pm \text { SD }\end{array}$ & $\Delta$ & p \\
\hline Control & $0.1976 \pm 0.0412^{\mathrm{a}}$ & $0.2047 \pm 0.0463^{\mathrm{a}}$ & -0.0071 & 0.432 \\
\hline S. officinalis 0.2\% & $0.1778 \pm 0.0528^{\mathrm{a}}$ & $0.2052 \pm 0.0440^{\mathrm{a}}$ & -0.0274 & $0.031^{\star}$ \\
\hline S. officinalis 0.8\% & $0.2065 \pm 0.0379^{\mathrm{a}}$ & $0.2073 \pm 0.0507^{\mathrm{a}}$ & -0.0008 & 0.945 \\
\hline S. officinalis 1.16\% & $0.1865 \pm 0.0442^{\mathrm{a}}$ & $0.2056 \pm 0.0556^{\mathrm{a}}$ & -0.0190 & 0.088 \\
\hline Chlorexidine 0.2\% & $0.1954 \pm 0.0407^{\mathrm{a}}$ & $0.1953 \pm 0.0453^{\mathrm{a}}$ & 0.0001 & 0.988 \\
\hline
\end{tabular}

* Indicates a statistically significant difference before (Day 1) and after (Day 30) the disinfection protocol (verified by paired t-test). The letters in the columns indicate statistically similar values between groups (One-way ANOVA, p>0.05).

of the disinfection protocol (Table 4). There was no statistically significant difference in roughness at the end of the disinfection protocol among the experimental groups (Table 4).

\section{Discussion}

This study tested the potential use of a natural substance that is easily available for simulated nighttime denture disinfection. In this sense, using strains isolated from the oral cavity of individuals provides a reliable representation of the clinical scenario and the virulence potential of these microorganisms. Our results revealed the potential use of the S. officinalis extract as disinfecting solution for dentures, proving true an antimicrobial and non-adherent effect against oral microorganisms, and not affecting substantially the surface roughness of the denture PMMA. Additionally, it should be noted that the results of this study are unique, considering most in vitro studies have used agar diffusion or broth dilution ${ }^{24-27}$.

An antimicrobial potential of the hydroalcoholic extract of $S$. officinalis against $C$. albicans, $S$. aureus, and $K$. oxytoca was revealed. This was expressed by reduction of microbial load. The antimicrobial effect is attributed to the oleanolic and ursolic acids, which are the two triterpenes present in $\mathrm{S}$. officinalis ${ }^{25}$. Although comparisons between the various concentrations of the extract did not present any statistically significant difference, superior antimicrobial effects were observed at the concentration 
of $1.16 \%$, suggesting that its effect is concentration-dependent. However, K. oxytoca was more sensitive to the effect of the extract, showing considerable reduction in CFU counts at all concentrations (Table 1). Our results, therefore, confirm the antimicrobial effect of $S$. officinalis against gram-positive and gram-negative bacteria and fungi, assigning this effect to terpenes and terpenoids ${ }^{13,24,27}$. This is promising, considering that the action of $S$. officinalis in soft tissue lesions against $S$. aureus, $K$. oxytoca, and C. albicans has been previously shown ${ }^{23-25}$.

Microbial adherence is responsible for biofilm formation in poorly sanitized dentures. Therefore, disinfecting substances that present a non-adherent effect are expected. Microbial adhesion tests on the PMMA surface showed a $2-\log C F U / \mathrm{mL}$ reduction in all experimental groups. the experimental solutions presented a significant non-adherent effect on the microoganisms tested in comparison with the saline solution, regardless of the concentration. For C. Albicans and K. oxytoca this effect was even similar to chlorhexidine digluconate, meaning that both substances present mechanisms to interfere on microbial adherence.

The fact that $K$. oxytoca was more sensitive to the extract contradicts a previous study ${ }^{26}$ in which gram-positive bacteria are generally more sensitive than gram-negative bacteria. Another study showed no antimicrobial effect of $S$. officinalis against $K$. oxytoca when the authors tested the essential oil25. However, the present study tested the hydroalcoholic extract, which reinforces the idea that the antimicrobial action of $S$. officinalis against gram-negative bacteria depends on the type of extract used ${ }^{26}$. The antimicrobial effect of the various concentrations of $S$. officinalis extract was similar to that of the $0.2 \%$ chlorhexidine solution, although, when compared individually, chlorhexidine presented superior results.

Treatment with $0.2 \%$ chlorhexidine solution for 5 min has been shown to produce death of $>4 \log 10$ of all tested microorganisms, including C. albicans ${ }^{28}$. Also, $0.2 \%$ chlorhexidine gluconate solution is effective in reducing microbial biofilm, suggesting that denture immersion in the solution at nighttime is sufficient to avoid the recurrence of the infection ${ }^{29}$. However, this product has been shown to cause discoloration of the PMMA of dentures, making it inappropriate for daily use.

The treatment with $0.2 \%$ chlorhexidine solution was the most effective in reducing $S$. aureus adherence, whereas in the case of $K$. oxytoca, the anti-adherent effect of all concentrations of $S$. officinalis extract was similar to that of chlorhexidine solution, which is considered a positive result. The adherence of $C$. albicans was considerably lower when exposed to the extract at concentration of $1.16 \%$, indicating the anti-adherent effect of this substance (Table 2).

Data on the anti-adherent activities of the hydroalcoholic extract of S. officinalis are scarce, particularly in regards to clinical isolates such as those tested in the present study. It is known that $S$. aureus presents several virulence determinants, which facilitate its adhesion to biotic and abiotic surfaces ${ }^{30}$. This may explain the higher adherence of this microorganism when compared to the others in the groups treated with S. officinalis.

Non-adherent effect of $S$. officinalis has been identified against three strains of $C$. albicans on the PMMA surface, even though the essential oil of the plant was used ${ }^{24}$. 
It also has been shown that the anti-adherent activity of $S$. officinalis is dose-dependent, and the action may be attributed to the monoterpenes present in the plant, which interact with the lipid components of the cell membrane ${ }^{24}$. This would increase its permeability and affect the electrolyte balance, consequently interfering with biofilm formation ${ }^{30}$. It was also observed that $S$. officinalis at $2.78 \mathrm{~g} / \mathrm{L}$ caused reductions between $89 \%$ and $96 \%$ in C. albicans adhesion to the PMMA surface when compared to the $96 \%$ to $98 \%$ reduction observed with $0.2 \%$ chlorhexidine ${ }^{24}$.

Color changes in PMMA specimens were not significantly different between the experimental groups at the end of the disinfection protocol, with all concentrations of $S$. officinalis producing a color change similar to that of the chlorhexidine solution (Table 3 ). The staining of PMMA resin by the disinfectant solutions is due to the accumulation of extrinsic pigments, but there is still controversy in the literature regarding color changes caused by chlorhexidine solution. Moffa et al. ${ }^{31}$ (2011) claimed to have stained this material with $2 \%$ chlorhexidine over a period of 6 months of exposure. Further studies should be dedicated to understanding the effects of the contact with $S$. officinalis extract, with particular emphasis on examining color change and antimicrobial effects of the extract on PMMA at shorter exposure times.

No significant increase in surface roughness was observed over the 30-day disinfection period (except for $0.2 \%$ S. officinalis). Therefore, the effect of S. officinalis was comparable to that of $0.2 \%$ chlorhexidine. The roughness findings of our study are similar to those reported by previous ones ${ }^{32}$. However, the lack of studies on S. officinalis extract and its potential implications on PMMA materials prevents deeper comparisons with other studies. Considering that roughness acts as a facilitator for microbial adhesion and biofilm formation, the absence of any significant change in surface roughness in this study may be perceived as favorable.

There is a clear demand for the efficient disinfection of dentures, which helps preventing lesions caused by pathogenic microorganisms in the oral cavity. In this sense, S. officinalis extract has shown potential to be used as a disinfectant solution for dentures by reducing the microbial load on the surface without significantly affecting its physical properties when compared to the standard disinfectant.

It may be concluded that the hydroalcoholic extract of S. officinalis is a potential disinfectant solution for dentures. The study hypothesis was partially confirmed, since color change resulting from the disinfection procedure, although, not different from the standard disinfectant, was clinically detectable. Further studies focusing on the action mechanism and potential toxicity effects on humans are still required. Clinical trials are essential to confirm the effectiveness results of the extract found in this in vitro study.

\section{Acknowledgements}

The authors acknowledge the essencial contribution of Ilce, Renata and Rafaela Lasta, both in providing potential patients for the study and in the production of the PMMA disks. The study had no financial support. The authors declare no conflict of interest. 


\section{References}

1. Santos CM, Hilgert JB, Padilha DMP, Hugo FN. Denture stomatitis and its risk indicators in south Brazilian older adults. Gerodontology. 2010 Jun;27(2):134-40. doi: 10.1111/j.1741-2358.2009.00295.x.

2. Martins N, Barros L, Santos-Buelga C, Henriques M, Silva S, Ferreira IC. Evaluation of bioactive properties and phenolic compounds in different extracts prepared from Salvia officinalis L. Food Chem. 2015 Mar 1;170:378-85. doi: 10.1016/j.foodchem.2014.08.096.

3. Vieira DRP, Amaral FMM, Maciel MCG, Nascimento FRF, Libério AS. [Plants and chemical constituents used in dentistry: review of ethnopharmacological and antimicrobial activity studies in oral pathogens]. Rev Bras Plantas Med. 2014;16(1):135-67. doi: 10.1590/\$1516-05722014000100020. Portuguese.

4. Zilberstein B, Quintanilha AG, Santos MA, Pajecki D, Moura EG, Alves PR et al. Digestive tract microbiota in healthy volunteers. Clinics (Sao Paulo). 2007 Feb;62(1):47-54.

5. Valentini F, Luz MS, Boscato N, Pereira-Cenci T. Biofilm formation on denture liners in a randomised controlled in situ trial. J Dent. 2013 May;41(5):420-7. doi: 10.1016/j.jdent.2013.02.012.

6. Mese A, Mese S. Effect of microwave energy on fungal growth of resilient denture liner material. Biotechnol Biotechnol Equip. 2014 Apr;21(1):91-3. doi: 10.1080/13102818.2007.10817422.

7. Quirynen $\mathrm{M}$, Bollen $\mathrm{CM}$. The influence of surface roughness and surface-free energy on supra- and subgingival plaque formation in man. A review of the literature. J Clin Periodontol. 1995 Jan;22(1):1-14.

8. Vasconcelos LR, Consani RLX, Mesquita MF, Sinhoreti MA. Effect of chemical and microwave disinfection on the surface microhardness of acrylic resin denture teeth. J Prosthodont. 2013 Jun;22(4):298-303. doi: 10.1111/jopr.12009.

9. Muscat Y, Farrugia C, Camilleri L, Arias-Moliz MT, Valdramidis V, Camilleri J. Investigation of acrylic resin disinfection using chemicals and ultrasound. J Prosthodont. 2018 Jun;27(5):461-468. doi: 10.1111/jopr.12511.

10. Panariello BH, Izumida FE, Moffa EB, Pavarina AC, Jorge JH, Giampaolo ET. Effect of mechanical toothbrushing combined with different denture cleansers in reducing the viability of a multispecies biofilm on acrylic resins. Am J Dent. 2016 Jun;29(3):154-60.

11. Peracini A, Machado Andrade I, Oliveira VC, Macedo AP, Silva-Lovato CH, Oliveira Pagnano V, et al. Antimicrobial action and long-term effect of overnight denture cleansers. Am J Dent. 2017 Apr;30(2):101-8.

12. Guiotti AM, Cunha BG, Paulini MB, Goiato MC, Dos Santos DM, Duque C et al. Antimicrobial activity of conventional and plant-extract disinfectant solutions on microbial biofilms on a maxillofacial polymer surface. J Prosthet Dent. 2016 Jul;116(1):136-43. doi: 10.1016/j.prosdent.2015.12.014.

13. Kon KV, Rai MK. Plant essential oils and their constituents in coping with multidrug-resistant bacteria. Expert Rev Anti Infect Ther. 2012 Jul;10(7):775-90. doi: 10.1586/eri.12.57.

14. Lorenzi H, Matos FJA. [Medicinal plants in Brazil: native and exotic]. São Paulo: Instituto Plantarum; 2002. 512 p. Portuguese.

15. ESCOP 1996. Salviae folium (Sage leaf). Monographs on the Medicinal Use of Plant Drugs. Exeter. UK: European Scientific Cooperative on Phytotherapy; 1997

16. Wichtl M. Herbal Drugs and Phytopharmaceuticals. Boca Raton, FL: CRC Press; 1994. p. 440-3.

17. Guiotti AM, Goiato MC, Dos Santos DM, Vechiato-Filho AJ, Cunha BG, Paulini MB et al. Comparison of conventional and plant-extract disinfectant solutions on the hardness and color stability of a maxillofacial elastomer after artificial aging. J Prosthet Dent. 2016 Apr;115(4):501-8. doi: 10.1016/j.prosdent.2015.09.009. 
18. Roman Junior WA, Picolli AL, Morais B, Loeblein M, Schönell AP. [Antiulcerogenic activity of aqueous extract of Salvia officinalis L. (Lamiaceae)]. Rev Bras PI Med. 2015;17(Suppl 1):774-81. doi: 10.1590/1983-084X/14_059. Portuguese.

19. Oliveira KB, Oliveira BH. HPLC/DAD determination of rosmarinic acid in Salvia officinalis: sample preparation optimization by factorial design. J Braz Chem Soc. 2013;24(1):85-91. doi: 10.1590/S0103-50532013000100012.

20. National Health Surveillance Agency (Brazil). [Brazilian pharmacopoeia]. 5. ed. Brasília: Anvisa; 2010. 546 p. Portuguese.

21. Abu-Bakr N, Han L, Okamoto A, Iwaku M. Color stability of compomer after immersion in various media. J Esthet Dent. 2000;12(5):258-63.

22. Commission Internationale de l'Eclairage - CIE. Colorimetrye official recommendations of the Commission Internationale de l'Eclairage (CIE Publication n. 15 - E-1.3.1). Vienna (France): Bureau Central de la CIE; 1996.

23. Tondo EC, Machado TRM, Malheiros Pda S, Padrão DK, de Carvalho AL, Brandelli A. Adhesion and biocides inactivation of Salmonella on stainless steel and polyethylene. Braz J Microbiol. 2010 Oct;41(4):1027-37. doi: 10.1590/\$1517-838220100004000022.

24. Sookto T, Srithavaj T, Thaweboon S, Thaweboon B, Shrestha B. In vitro effects of Salvia officinalis L. essential oil on Candida albicans. Asian Pac J Trop Biomed. 2013 May;3(5):376-80. doi: 10.1016/S2221-1691(13)60080-5.

25. Fournomiti M, Kimbaris A, Mantzourani I, Plessas S, Theodoridou I, Papaemmanouil V, et al. Antimicrobial activity of essential oils of cultivated oregano (Origanum vulgare), sage (Salvia officinalis), and thyme (Thymus vulgaris) against clinical isolates of Escherichia coli, Klebsiella oxytoca, and Klebsiella pneumoniae. Microb Ecol Health Dis. 2015 Apr 15;26:23289. doi: $10.3402 /$ mehd.v26.23289.

26. Koslowska M, Laudy AE, Przybyl J, Ziarno M, Majewska E. Chemical composition and antibacterial activity of some medicinal plants from Lamiaceae family. Acta Pol Pharm. 2015 Jul-Aug;72(4):757-67.

27. Horiuchi K, Shiota S, Kuroda T, Hatano T, Yoshida T, Tsuchiya T. Potentiation of Antimicrobial Activity of Aminoglycosides by Carnosol from Salvia officinalis. Biol Pharm Bull. 2007 Feb;30(2):287-90.

28. Kiesow SA, Sarembe S, Pizzey RL, Axe AS, Bradshaw DJ. Material compatibility and antimicrobial activity of consumer products commonly used to clean dentures. J Prosthet Dent. 2016 Feb;115(2):189-198.e8. doi: 10.1016/j.prosdent.2015.08.010.

29. Gonçalves LFF, Silva Neto DR, Bonan RF, Carlo HL, Batista AUD. [Complete and Partial Removable Dentures Cleansing Methods. Rev Bras Cienc Saude. 2011;15(1):87-94. doi: 10.4034/RBCS.2011.15.01.13. Portuguese.

30. Foster TJ, Geoghegan JA, Ganesh VK, Höök M. Adhesion, invasion and evasion: the many functions of the surface proteins of Staphylococcus aureus. Nat Rev Microbiol. 2014 Jan;12(1):49-62. doi: 10.1038/nrmicro3161.

31. Moffa EB, Giampaolo ET, Izumida FE, Paravina AC, Machado AL, Vergani CE. Color stability of relined dentures after chemical disinfection. A randomised clinical trial. J Dent. 2011 Dec;39 Suppl 3:e65-71. doi: 10.1016/j.jdent.2011.10.008.

32. Schwindling FS, Rammelsberg P, Stober T. Effect of chemical disinfection on the surface roughness of hard denture base materials: a systematic literature review. Int J Prosthodont. 2014 May-Jun;27(3):215-25. doi: 10.11607/ijp.3759. 